\title{
Las instituciones religiosas en la transformación normativa contemporánea en la sexualidad en Chile ${ }^{1}$
}

\author{
The religious institutions in the contemporaneous \\ normative transformation of sexuality in Chile
}

Irma Palma ${ }^{2}$

\begin{abstract}
Resumen
Este texto analiza la relación entre orientaciones normativas de las instituciones religiosas y las prácticas sexuales de los sujetos, más precisamente los efectos de la adscripción y la observancia en contexto de transformación tanto de las religiones como de sexualidad en la sociedad chilena contemporánea. Se analiza la Encuesta Nacional de Comportamiento Sexual, realizada en 1998 por la Comisión Nacional del SIDA, CONASIDA, con la colaboración de la Agence Nationale de Recherches sur le SIDA, ANRS, de Francia, con sujetos nacidos entre 1929 y 1978 ( $\mathrm{N}$ = 5407). El análisis muestra los efectos de género producidos por la observancia, más intensos sobre las mujeres y diferenciados por lógicas de individualización entre católicas, y de subjetivación comunitaria, entre evangélicas; también muestra las transformaciones generacionales de la secularización y la reducción progresiva de los efectos de las instituciones religiosas sobre las prácticas de los sujetos.

Palabras clave: religión, sexualidad, normas.
\end{abstract}

\begin{abstract}
This paper analyzes the relation between religious institutions normative orientations and the sexual practices of subjects, more precisely the effects of the adscription and observance in the context of the transformation of religion as well as the sexuality in the contem-
\end{abstract}

La autora agradece la colaboración en la selección y procesamiento de los datos a Christian Beyle, Michel Lapierre y Pablo Sandoval, y los comentarios de Michel Bozon y Samuel Palma.

2 Doctora en Psicología, académica del Departamento de Psicología, Universidad de Chile. ipalma@uchile.cl 
porary Chilean society. It analyzes the National Survey on Sexual Comportment, that was done in the year 1998 by the National Commission on HIV/AIDS, CONASIDA, with the collaboration of the Agence Nationale de Researches sur le SIDA, ANRS, France, with people that were born between 1929 and 1978 ( $N=5407)$. The analysis shows the effects on gender produced by observance, more intense on women differentiated by individualization logics, among the catholic, and of communitarian subjectivity, among evangelical women; it also shows the generational transformations of secularization and the progressive reduction of the effects of religious institutions on the subjects practices.

Keywords: religion, sexuality, norms 


\section{Introducción}

La sexualidad constituye una experiencia, al mismo tiempo, personal e histórica. Se sitúa tanto en el nivel de los individuos como de las relaciones entre éstos, y de las relaciones de éstos con las instituciones, y su construcción y su transformación se realizan en el proceso mismo en que se construye y se transforma la realidad social. Por ello, constituye una auto-producción social, una construcción humana en que la propia auto-observación o la propia reflexividad de las prácticas configura lo que es social e individualmente posible, imaginable, significativo. En tal sentido, la sexualidad ha cambiado y está cambiando en la sociedad chilena; ello resulta manifiesto tanto a la observación especializada como al sentido común. Se trata de una transformación en curso que opera en las prácticas, significados y representaciones, en los ordenamientos simbólicos, en las configuraciones de las interacciones y relaciones, en las trayectorias sexuales, en la constitución de identidades sociales sexuadas, entre otras. Se ubica tanto en el nivel de los individuos como de las relaciones entre éstos, y de las relaciones de éstos con las instituciones.

A su vez, la religión puede ser observada como "una estructura de discurso y de práctica compartida por un grupo social y referida a alguna fuerza -personalizada o no, múltiple o singular- a la cual los creyentes consideran anterior y superior a su contexto social y natural y ante la cual sienten una cierta dependencia -creados, gobernados, protegidos, amenazados, etc.- con respecto a la cual se consideran a sí mismos obligados a acatar ciertas normas de comportamiento en relación a los demás" (Maduro, O., 1978, pp. 33-34). Así definida, la religión opera como una fuerza homogeneizante de discursos y prácticas al interior de una comunidad humana y, en esa medida, opera una normatividad sobre dichos discursos y prácticas. En la medida en que la sexualidad constituye una dimensión fundamental de la experiencia individual y social, también constituye un campo de construcción normativa de la religión. De manera bastante distinta, Hill (Hill, M., 1976) sugiere que los significados de la religión se presentan histórica, geográfica, cultural y demográficamente situados en cada comunidad de habla; por ello, son complejos, diversos y en muchos sentidos confusos. Sobre todo porque la religión puede entenderse, en la sociedad contemporánea, como en un diálogo permanente con la secularización; los significados mismos de la experiencia o de la observancia religiosa se construyen a la luz de la creciente secularización de la sociedad. ${ }^{3}$ Así, cada una de las definiciones de religión mencionada destaca un aspecto que resulta relevante para nuestro estudio: la primera, la capacidad nor-

Entre otros aspectos, ello supone que la individualización que caracteriza a la secularización pone en el ámbito del individuo muchas decisiones y opciones que antes dejaba en manos de la institucionalidad o de la comunidad religiosa. Es el individuo quien tiene que compatibilizar su observancia religiosa con su vivencia de la sociedad secular y de la individualización. 
mativa de la religión, particularmente en referencia a una comunidad o grupo de lenguaje y experiencia; la segunda, el carácter histórico y, por tanto, cambiante de la religión, en interacción activa con la transformación de la sociedad.

La relación entre religión y sexualidad constituye un tema de debate, tanto en el campo de la ciencia, de la política o de la cultura, en el de la vida cotidiana y de los sentidos comunes. En ambos casos, se trata de fenómenos que comprometen múltiples dimensiones de la vida personal y social y que, por ello, se entrecruzan, se influyen mutuamente y, en varios sentidos, se confunden. Sobre todo, la relación entre ambos se ha modificado y se modifica en el mismo proceso en que se transforma la sociedad. Por ello, se constituye también en un importante campo de estudio e investigación social.

La transformación religiosa en la sociedad chilena, particularmente a lo largo del siglo veinte, ha tenido que ver con la emergencia de nuevas religiones -la principal de ellas, la religión "evangélica"- y con la secularización, el cual se ha traducido en decrecimiento de la observancia religiosa. En el primer caso, se trata de una transformación que no necesariamente representa una alternativa radical a la normatividad tradicional católica respecto de la sexualidad; en el segundo, se trata de una transformación que pone en juego la autonomía e individualización de sus miembros. En efecto, la transformación de la sexualidad, en la sociedad chilena, ha tenido que ver con una creciente autonomía de los individuos para tomar decisiones respecto de su propia sexualidad, con prescindencia, o al menos con distancia, de las normatividades institucionales, incluyendo las instituciones religiosas. En este sentido, la transformación de la sexualidad se presenta asociada a un desplazamiento normativo de dichas instituciones, desplazamiento que no compromete necesariamente la adscripción religiosa de los individuos.

El presente trabajo explora las relaciones entre sexualidad y religión, a la luz de los resultados de la más importante encuesta nacional sobre comportamiento sexual desarrollada en la sociedad chilena. Tres conceptos pasan a ser centrales en esta aproximación: adscripción, observancia y secularización. El primero alude a una auto-identificación con alguna religión; el segundo alude a la intensidad de un involucramiento en el quehacer de una institucionalidad religiosa; a su vez, el término "secularización" expresa, aunque de manera restrictiva, la ampliación del campo de posiciones y decisiones que los individuos pueden asumir con prescindencia de las posiciones y decisiones que adopten las instituciones religiosas.

A este respecto, la encuesta "Los católicos opinan", realizada por Adimark en 2005, señala que, del total de la población católica incluida en la muestra, un 59\% aprueba que los sacerdotes puedan contraer matrimonio, un 60\% afirma ser partidario que se permita a las mujeres ser ordenadas como sacerdotes y un $75 \%$ dice ser partidario de que los obispos fueran elegidos por los sacerdotes y fieles de las diócesis; también, un $74 \%$ aprueba que los divorciados vueltos a casar sean admitidos a la 
comunión; finalmente, un 95\% aprueba el uso del condón como medio de prevenir el Sida y un $95 \%$ afirma que las parejas debieran ser libres de escoger el método de control de la natalidad que prefieran. Datos similares se observan en dicha encuesta respecto de la religión evangélica y otras religiones. Una encuesta El MercurioOpina, en el mes de marzo de 2006, arroja resultados similares. Esta indica que del total de la población católica incluida en la muestra, un $77 \%$ opina que la Iglesia Católica debiera permitir el uso de anticonceptivos; un 48\% que debiera permitir a los sacerdotes el matrimonio; un 51\% que debiera permitir el sacerdocio en las mujeres; y un $72 \%$ que debiera permitir el divorcio a los católicos.

Como se observa, las percepciones y opiniones de la población difieren notablemente de los preceptos y orientaciones normativas de las instituciones religiosas acerca de la sexualidad, sin que por ello se ponga en juego la adscripción religiosa de dicha población. No obstante, también muestran a un número menor pero significativo de individuos que opinan de manera distinta y, en general, opuesta a la mayoría; podemos asumir que tales individuos, a su vez, presentan grados mayores de intensidad en su observancia religiosa, es decir, en términos prácticos, en la frecuencia con que participan en las actividades de sus respectivas instituciones religiosas.

Nos preguntamos por la eficacia normativa de las instituciones religiosas en los individuos a través de su adscripción y su observancia religiosa.

\section{Análisis de los datos de estudio}

Lo que presentamos a continuación es propiamente un análisis de un conjunto de datos generados en el país, que fundamentan y dan sentido a la hipótesis aquí formulada; sirven al propósito de mostrar las tendencias que se enuncian y, dado que corresponden a una década atrás, expresan insuficientemente magnitudes de cada uno de los aspectos considerados, los cuales pueden haber cambiado en este periodo; no obstante, puede sugerirse que su estructura se transforma en tiempos más largos. Utiliza la Base de Datos correspondiente a la Encuesta Nacional de Comportamiento Sexual, realizada en 1998 por la Comisión Nacional del SIDA, CONASIDA, con la colaboración de la Agence Nationale de Recherches sur le SIDA, ANRS, de Francia. ${ }^{4}$ Estudia prácticas, no analiza discursos normati-

\footnotetext{
La población objetivo comprendió a personas de 18 a 69 años de edad, es decir, sujetos nacidos entre los años 1929 y 1980. Este estudio fue de cobertura nacional urbana, consideró ciudades de 100.000 habitantes o superior, y se basó en una muestra probabilística trietápica, estratificada por ciudades. La muestra representa aproximadamente al $80 \%$ de la población urbana nacional. Se confeccionó una muestra teórica total de 8.000 encuestas a realizar, desagregadas en 6000 encuestas y 2000 adicionales por el efecto de la no respuesta, obteniendo en el levantamiento de la información una muestra efectiva de 5407 encuestas válidas. De modo referencial, a nivel nacional, con la presencia de un atributo en un $50 \%$,
} 
vos; hace esta opción porque justamente es en las prácticas donde se expresan más individualmente las relaciones entre individuos e instituciones; si se quiere decir de otro modo, en el orden del hacer.

Analizamos un conjunto de comportamientos asociados a momentos de las trayectorias sexuales de los sujetos: primero, dos elementos iniciales y remotos en las trayectorias biográficas, a saber, los contextos de la entrada en la sexualidad activa: edades de iniciación sexual y tipo vínculo con la primera pareja sexual; luego, abordamos un elemento más longitudinal, que expresa un periodo relativamente largo y próximo en el tiempo, el número de parejas sexuales durante los últimos cinco años; finalmente, tratamos un elemento aún más reciente, el de las prácticas sexuales. Distinguimos en lo religioso "adscripción religiosa” y "observancia religiosa". ${ }^{56} \mathrm{La}$ Encuesta CONASIDA/ANRS incluyó tres preguntas relativas a la variable religiosa: religión de origen, adscripción religiosa actual y frecuencia de asistencia a servicio religioso. Lo último constituye un indicador del nivel de religiosidad o de observancia religiosa. La religión de origen podría referir a la (o las) matriz común, a su evolución temporal en la sociedad chilena, así como a la movilidad y reproducción generacional de las religiones y de la laicidad. Las tablas siguientes contienen antecedentes acerca de la distribución de pertenencia y observancia religiosas de la población aquí investigada. ${ }^{7}$ La proporción de católi-

que corresponde a la varianza máxima, se consideró un error absoluto de $1.4 \%$ con $95 \%$ de confianza. La muestra observada estaba compuesta por un total de 2244 (41.5\%) hombres y $3163(58.5 \%)$ mujeres. Dada la sub-representación masculina de la muestra, se aplicó un factor de expansión poblacional. La recolección de datos se realizo mediante entrevista cara a cara entre encuestador y entrevistado y mediante la auto-aplicación de secciones predefinidas en este formato. El instrumento de recogida de datos diseńado para este estudio fue una encuesta de conducta sexual y de riesgo ante el VIH. Se construyó y consolidó un cuestionario con preguntas básicamente cerradas y desagregadas. Los siguientes fueron los bloques de preguntas: características socio-demográficas, comunicación y normas, iniciación sexual, protección y uso preservativo, relacional última pareja y penúltima pareja, comercio sexual, violencia y ITS, experiencia sexual, orientación sexual, SIDA e ingresos.

5 Consideramos como "adscripción religiosa" a la auto-identificación con alguna de las religiones existentes en la sociedad chilena y tipificadas en los instrumentos de investigación o de medición utilizados en la Encuesta CONASIDA/ANRS (Católico, Evangélico, Otra religión, Sin Religión). Por su parte, la categoría de "observancia” tiene el sentido de frecuencia en la participación en servicios o actividades religiosas u organizadas por instituciones religiosas que se ha indicado precedentemente. A su vez, el término "secularización" expresa (aunque de manera restrictiva) la ampliación del campo de posiciones y decisiones que los individuos pueden asumir con prescindencia de las posiciones y decisiones que adopten las instituciones religiosas.

6 Usamos operacionalmente las nociones de practicante un no practicante. Practicante es quien responde a una asistencia de "una o más veces a la semana" y "una o más veces al mes"; no practicante es quien responde "Algunas veces en el año" y "nunca".

7 Se deja fuera del análisis a los sujetos adscritos a "otra religión” por alcanzar sólo al 4.1\% de la población estudiada. Su exclusión no afecta a la hipótesis desarrollada. 
cos no ha dejado de declinar en las últimas generaciones (representan tres cuartos de la población en la generación más antigua; en la generación más reciente son dos tercios de las mujeres, y tres quintos de los hombres), aumenta levemente la proporción de hombres evangélicos, y se mantiene la de mujeres (una mujer cada seis), y aumenta fuertemente la proporción de los que no refieren ninguna adscripción, especialmente entre los hombres (uno de cada cinco en la generación joven). En el universo de las personas religiosas, cambia de manera muy fuerte la proporción de los observantes: en la generación antigua, tres quintos de las católicas y tres cuartos de las evangélicas son practicantes, en la generación joven, las proporciones caen a $25 \%$ y a $49 \%$ respectivamente; siempre menos practicantes que las mujeres, los hombres católicos alcanzan en la generación joven niveles muy bajos de observancia en comparación con los evangélicos (19\% vs 35\%).

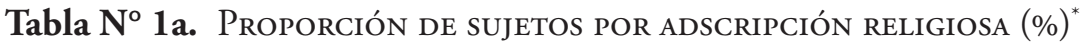

\begin{tabular}{|c|c|c|c|c|c|c|c|c|}
\hline Sexo & Edad & $\%$ & Católica & Evangélica & Otra & Ninguna & Total & N \\
\hline \multirow{5}{*}{ Mujer } & 20 a 29 & $\%$ & 67,6 & 17,5 & 3,9 & 10,9 & 100 & 696 \\
\cline { 2 - 9 } & 30 a 49 & $\%$ & 73,7 & 15,6 & 4,5 & 6,2 & 100 & 1533 \\
\cline { 2 - 9 } & 50 a 69 & $\%$ & 76,2 & 16,9 & 4,0 & 3,0 & 100 & 783 \\
\cline { 2 - 9 } & Total & $\%$ & 72,7 & 16,4 & 4,2 & 6,7 & 100 & \\
\cline { 2 - 9 } & $\mathrm{N}$ & $\%$ & 2163 & 517 & 128 & 204 & & 3012 \\
\hline \multirow{5}{*}{ Hombre } & 20 a 29 & $\%$ & 61,8 & $\mid 4,2$ & 3,0 & 21,1 & 100 & 550 \\
\cline { 2 - 9 } & 30 a 49 & $\%$ & 72,1 & 12,3 & 4,8 & 10,8 & 100 & 1066 \\
\cline { 2 - 9 } & 50 a 69 & $\%$ & 75,0 & 10,7 & 3,8 & 10,6 & 100 & 518 \\
\cline { 2 - 9 } & Total & $\%$ & 69,6 & 12,5 & 4,0 & 13,8 & 100 & \\
\cline { 2 - 9 } & $\mathrm{N}$ & $\%$ & $\mid 462$ & 293 & 85 & 294 & & 2134 \\
\hline
\end{tabular}

* Base: Encuesta CONASIDA/ANRS 1998, entrevistados de 20 a 69 años.

Tabla N $^{\circ}$ 1b. Proporción de sujetos por observancia Religiosa

\begin{tabular}{|c|c|c|c|c|c|c|c|c|c|c|}
\hline \multirow[b]{2}{*}{ Edades } & \multirow[b]{2}{*}{$\begin{array}{l}\text { Adscrip- } \\
\text { tion }\end{array}$} & \multirow[b]{2}{*}{$\%$} & \multicolumn{4}{|c|}{ Mujeres } & \multicolumn{4}{|c|}{ Hombres } \\
\hline & & & $\begin{array}{c}\text { No prac- } \\
\text { ticante }\end{array}$ & $\begin{array}{l}\text { Practi- } \\
\text { cante }\end{array}$ & Total & $\mathrm{N}$ & $\begin{array}{l}\text { No prac- } \\
\text { ticante }\end{array}$ & $\begin{array}{l}\text { Practi- } \\
\text { cante }\end{array}$ & Total & $N$ \\
\hline \multirow{3}{*}{20 a 29} & Católica & $\%$ & 74,6 & 25,4 & 100 & 467 & 81,4 & 18,6 & 100 & 344 \\
\hline & Evangélica & $\%$ & 51,3 & 48,7 & 100 & 126 & 65,4 & 34,6 & 100 & 74 \\
\hline & Total & $\%$ & 69,8 & 30,2 & 100 & 593 & 78,4 & 21,6 & 100 & 418 \\
\hline \multirow{3}{*}{$30-49$} & Católica & $\%$ & 49,3 & 50,7 & 100 & 1104 & 70,2 & 29,8 & 100 & 736 \\
\hline & Evangélica & $\%$ & 34,9 & 65,1 & 100 & 263 & 39,6 & 60,4 & 100 & 154 \\
\hline & Total & $\%$ & 46,9 & 53,1 & 100 & 1367 & 65,7 & 34,3 & 100 & 890 \\
\hline \multirow{3}{*}{50 a 69} & Católica & $\%$ & 38,2 & 61,8 & 100 & 592 & 54,6 & 45,4 & 100 & 382 \\
\hline & Evangélica & $\%$ & 24,8 & 75,2 & 100 & 128 & 31,5 & 68,5 & 100 & 65 \\
\hline & Total & $\%$ & 35,7 & 64,3 & 100 & 720 & 51,7 & 48,3 & 100 & 447 \\
\hline
\end{tabular}




\section{La estructura de edades en la entrada en la sexualidad activa: la generación joven}

Los calendarios asociados al proceso de entrada en la sexualidad activa de un individuo expresan las condiciones culturales, sociales, económicas y políticas específicas en que él (o ella) y la sexualidad se inscriben, y cómo se organizan y expresan tanto en las trayectorias biográficas, como en las relaciones entre individuos y entre éstos y las instituciones. Por ello, los calendarios se han constituido en un indicador de transformaciones culturales y sociales en las sociedades occidentales contemporáneas. La transformación de los proceso de entrada en la sexualidad activa ha sido observada básicamente en la temporalidad (sincronías o a-sincronías) de un conjunto de fenómenos que tienen como eje las relaciones de género, a saber, la proximidad (o distancia) de los calendarios de iniciación sexual, la reducción (o no) de las divergencias en las edades de los actores -hombres y mujeres- en el proceso de iniciación sexual en las generaciones, las distancias (o proximidades) de tal suceso respecto de la reproducción biológica -la maternidad, principalmente-, la introducción de tecnología preventiva en la primera y posteriores relaciones sexuales. Puede observarse también como un indicador de la configuración específica de la estructuración social de las edades, en particular como organización de los itinerarios y trayectorias sexuales y socio-afectivas prescritas o indicadas por instituciones, colectivos o comunidades, como expresión de procesos de autonomización de los sujetos en las sociedades contemporáneas, en su conexión con una diversificación de procesos de construcción de las uniones, de inserción laboral, etc.

La pertenencia a una religión impacta sobre la estructura de las edades, y lo hace fundamentalmente sobre las mujeres, más especialmente sobre las evangélicas (véase Tabla $\mathrm{N}^{\circ}$ 2). La pertenencia religiosa presenta estructuras etarias de iniciación sexual diferenciadas en la generación estudiada (jóvenes entre 20 y 29 años). ${ }^{8}$ Los sujetos no creyentes lo hacen mucho más tempranamente (78\% lo hace antes de cumplir veinte ańos y $6 \%$ permanece no iniciado en el momento de la encuesta), católicos lo hacen en niveles más próximos a evangélicos (68\% lo hace antes de cumplir veinte años y $10 \%$ está sin iniciarse), los que presentan una $65 \%$ de sujetos iniciados antes de cumplir veinte ańos y a $17 \%$, sin iniciarse. Esta diferencia se encuentra atravesada por las configuraciones de las relaciones de género.

Consideramos a los sujetos entre 20 y 29 años, de manera de reducir la distancia temporal entre iniciación y presente, periodo susceptible a la movilidad religiosa. 
Tabla $\mathbf{N}^{\circ}$ 2. EdADES De INICIACIÓN SEXUAL DE JÓVENES (20-29 AÑOS), SEGÚN ADSCRIPCIÓN RELIGIOSA Y SEXO (\%) (N: I I 78)

\begin{tabular}{|l|c|c|c|c|c|c|c|c|c|c|c|c|c|}
\hline & \multicolumn{4}{|c|}{ Católica } & \multicolumn{3}{c|}{ Evangélica } & \multicolumn{3}{c|}{ Ninguna } & \multicolumn{3}{c|}{ Total } \\
\cline { 2 - 18 } & & M & H & Total & M & H & Total & M & H & Total & M & H & Total \\
\hline Menos de 20 años & $\%$ & 60 & 77 & 68 & 52 & 82 & 65 & 68 & 82 & 78 & 59 & 79 & 69 \\
\hline Más de 20 años & $\%$ & 25 & 18 & 22 & 25 & 8 & 18 & 29 & 10 & 16 & 26 & 15 & 20 \\
\hline Vírgenes & $\%$ & 15 & 5 & 10 & 23 & 10 & 17 & 3 & 8 & 6 & 15 & 6 & 11 \\
\hline Total & $\%$ & 100 & 100 & 100 & 100 & 100 & 100 & 100 & 100 & 100 & 100 & 100 & 100 \\
\hline
\end{tabular}

Entre hombres y mujeres existen diferencias en sus edades de entrada en la sexualidad activa. Como puede observarse en la Tabla $\mathrm{N}^{\circ} 2$, las mujeres se inician en la adolescencia en una menor proporción que los hombres (59\% vs. $79 \%)$; al mismo tiempo, los sujetos no iniciados aún (tardíos) alcanzan a 15\% de mujeres y sólo a $6 \%$ de hombres. Las mujeres y hombres presentan diferencias más o menos intensas en las distintas adscripciones. A hombres y mujeres evangélicos les separan treinta puntos porcentuales de iniciados en la adolescencia y doce en sus niveles de virginidad (23\%, en ellas, lejos el más alto entre todos), a católicos les separan diez y siete puntos de iniciados en la adolescencia y nueve en sus niveles de virginidad, y a no creyentes les separan trece puntos de iniciados en la adolescencia y cuatro en sus niveles de virginidad, a favor de las mujeres. A su vez, las mujeres presentan diferencias en los niveles en que permanecen vírgenes. Mientras las evangélicas permanecen vírgenes en una mayor proporción (23\%), las no creyentes lo hacen en una mínima proporción (3\%), las católicas, en tanto, se ubican en medio de las anteriores (15\%). En sentido contrario, los hombres presentan similitudes importantes entre sí, la iniciación en la adolescencia les compromete en proporciones elevadas. Observados desde uno de principales indicadores del proceso de transformación de las sexualidades juveniles, la sincronización de calendarios, hombres y mujeres, presentan en su estructuración de las edades una distancia manifiesta que implica a las mujeres jóvenes evangélicas, de entrada más tardía en la sexualidad activa.

La observancia introduce una diferencia en la estructuración social de las edades de iniciación sexual. Impacta sobre las edades en su retardación (véase Tabla $\mathrm{N}^{\circ}$ 3). Pero no lo hace homogéneamente en las religiones, ni sobre hombres y mujeres. En general, no practicantes y practicantes se diferencian en la precocidad y tardanza. Observados en sus niveles de virginidad, los hombres no practicantes presentan $4 \%$, los otros alcanzan a $13 \%$; las mujeres no practicantes presentan $14 \%$ y las otras, $22 \%$. Pero al mismo tiempo, observadas las adscripciones, puede observarse que los efectos son más profundos sobre las mujeres en ambas religiones, y entre los hombres impacta sobre los de adscripción evangélica. 
Tabla Nº 3. Edades de iniciación SeXual de jóvenes (20-29 AÑos), SEGÚN ADSCRIPCIÓN, OBSERVANCIA RELIGIOSA Y SEXO (\%) (N: II78)

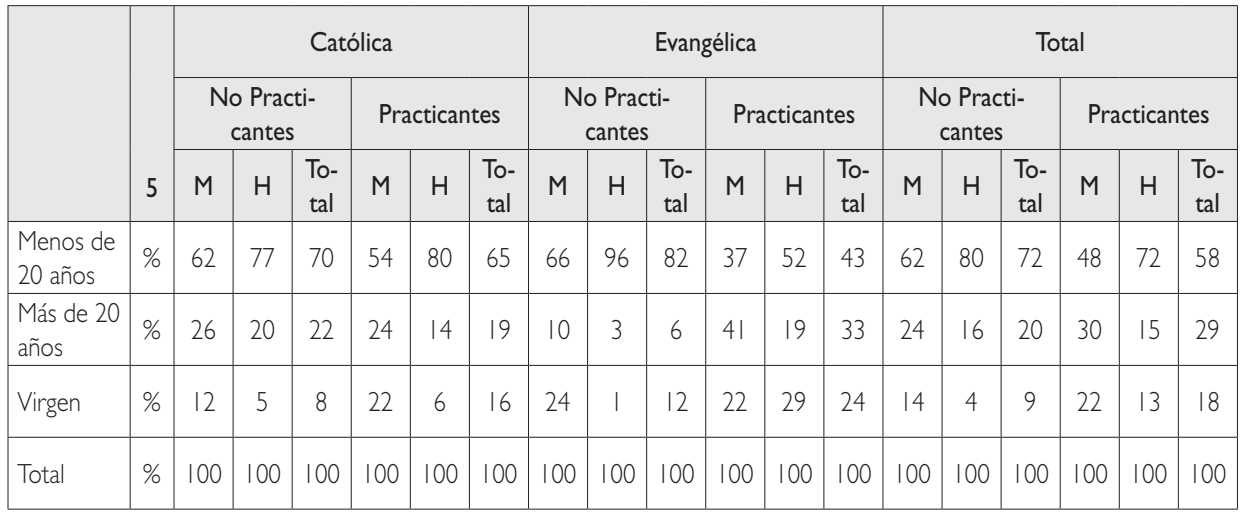

\section{La transformación de los contextos en la entrada en la sexualidad activa en las generaciones}

La sociedad chilena ha experimentado, desde las generaciones nacidas en la década de 1950, una evolución sistemática hacia una iniciación sexual en contextos no maritales por parte de las mujeres, y de una transformación interna de antiguos contextos no maritales por parte de los hombres. ${ }^{9}$ También se ha producido un descenso en la edad de la primera relación sexual en las mujeres y una tendencia a su concentración en ciertas edades, junto una elevación de las edades de las uniones. En esta perspectiva, una iniciación sexual marital resulta excepcional en las nuevas generaciones.

La entrada en la sexualidad activa puede organizarse bajo contextos relacionales, de ocasionalidad o de sociabilidad. Todos éstos se definen por los tipos de vínculos implicados y por su institucionalización; desde los más altamente vinculantes e institucionales (iniciación marital) hasta los más prescindentes de vínculos y des-institucionalizados (en el episodio con un recién conocido). Un contexto relacional se orienta por una lógica de vínculo reconocible como pareja, pero distingue fuertemente entre pololeo/noviazgo y matrimonio, entre iniciación llamada pre-marital y marital. Como sosteníamos antes, uno de los elementos más

9 En la generación más joven aquí analizada, nueve de cada diez jóvenes que cursan la tercera década han hecho su entrada en la sexualidad activa (90\%); $85 \%$ de mujeres y $94 \%$ de hombres. 
tempranos y cruciales de la transformación en las prácticas ocurridos en nuestra sociedad es la iniciación femenina fuera del matrimonio; ello inaugura un contexto relacional no institucional, en el cual se concentra crecientemente la entrada en la sexualidad activa en las generaciones más jóvenes, al que llegan las mujeres después de haber abandonado la iniciación marital en décadas pasadas, y se suman progresivamente los hombres, después de ir abandonando una iniciación en contexto de ocasionalidad. ${ }^{10}$

Las generaciones aquí analizadas se ubican en un proceso cultural de transformación de estructuras altamente diferenciadas para hombres y mujeres. ${ }^{11}$ La generación de mujeres de edades medianas (nacidas entre 1949 y 1968, y estudiadas cuando tienen entre 30 y 49 años) expresa una transformación en tal estructura contextual: un contexto relacional fuertemente marital da paso a uno denominado en su tiempo pre-marital: se invierte la tendencia entre matrimonio y noviazgo/pololeo, más intensamente entre las mujeres sin adscripción religiosa (véase Tabla $\mathrm{N}^{\circ} 4$ ). Entre las mujeres creyentes, un 60\% y 64\% de evangélicas y católicas se inician sexualmente en el noviazgo o pololeo), y lo hace en el matrimonio un 37\% y 32\%, respectivamente; las mujeres no adscritas a religión alguna invierten aún más la tendencia precedente (28\% y 69\%). Con ello esta generación de mujeres produce la diferenciación de dos procesos conectados sincrónicamente en sus calendarios, a saber, la entrada en la sexualidad activa y en las uniones; proceso que alcanza a todas las adscripciones religiosas, especialmente a las no creyentes. La generación más joven evoluciona hacia la reducción sustantiva del contexto marital de iniciación entre las mujeres (9\%). Las jóvenes profundizan la tendencia anterior; sin embargo, a pesar que todas lo reducen, lo hacen diferenciadamente según sus adscripciones religiosas, hecho que puede ser comprendido también a partir de la observancia. Es más lenta generacionalmente entre evangélicas, o más situada en núcleos más practicantes; las católicas descienden de un nivel de $32 \%$ en la generación anterior a un $6 \%$ en la actual, las no creyentes pasan de un nivel de $28 \%$ a un $1 \%$, y las evangélicas transitan desde un $37 \%$ a sólo un $25 \%$.

10 Véase: I. Palma, 2006.

11 También aquí consideramos a los sujetos menores de cincuenta años, de manera de reducir la distancia temporal entre iniciación y presente, periodo susceptible a la movilidad religiosa. 
Tabla No 4. ConteXto de INICIACión SEXUAL, SEgÚN ADSCRIPCiÓN RELIGIOSA, EDAD Y SEXO (\%) (N: 3532)

\begin{tabular}{|c|c|c|c|c|c|c|c|c|c|c|c|c|c|c|}
\hline \multirow{2}{*}{ Edades } & & & \multicolumn{3}{|c|}{ Católica } & \multicolumn{3}{|c|}{ Evangélica } & \multicolumn{3}{|c|}{ Ninguna } & \multicolumn{3}{|c|}{ Total } \\
\hline & & & $M$ & $\mathrm{H}$ & Total & $M$ & $\mathrm{H}$ & Total & $M$ & $\mathrm{H}$ & Total & M & $\mathrm{H}$ & Total \\
\hline \multirow{6}{*}{ 20-29 } & $\begin{array}{l}\text { R. conocido } \\
\text { Com. sexual }\end{array}$ & $\%$ & I & 11 & 6 & 0 & 15 & 7 & 3 & 14 & 11 & I & 12 & 7 \\
\hline & Amigo(a) & $\%$ & 4 & 33 & 20 & 3 & 46 & 24 & 10 & 32 & 25 & 5 & 35 & 21 \\
\hline & Esposo(a) & $\%$ & 6 & 1 & 3 & 25 & 0 & 13 & 1 & 2 & 2 & 9 & 1 & 5 \\
\hline & Pololo(a) & $\%$ & 89 & 54 & 70 & 72 & 38 & 55 & 86 & 49 & 61 & 85 & 51 & 66 \\
\hline & Otro & $\%$ & 0 & I & 1 & 0 & 1 & 1 & 0 & 3 & 2 & 0 & 1 & I \\
\hline & Total & $\%$ & 100 & 100 & 100 & 100 & 100 & 100 & 100 & 100 & 100 & 100 & 100 & 100 \\
\hline \multirow{6}{*}{$30-49$} & $\begin{array}{l}\text { R. conocido } \\
\text { Com. sexual }\end{array}$ & $\%$ & 0 & 16 & 7 & I & 16 & 7 & 0 & 19 & 11 & 0 & 17 & 8 \\
\hline & Amigo(a) & $\%$ & 3 & 38 & 19 & 2 & 28 & 13 & 3 & 37 & 23 & 3 & 36 & 18 \\
\hline & Esposo(a) & $\%$ & 32 & 4 & 20 & 37 & 13 & 27 & 28 & 3 & 14 & 33 & 5 & 20 \\
\hline & Pololo(a) & $\%$ & 64 & 38 & 52 & 60 & 41 & 52 & 69 & 37 & 51 & 64 & 38 & 52 \\
\hline & Otro & $\%$ & 1 & 4 & 2 & 0 & 3 & 1 & 0 & 4 & 2 & 0 & 4 & 2 \\
\hline & Total & $\%$ & 100 & 100 & 100 & 100 & 100 & 100 & 100 & 100 & 100 & 100 & 100 & 100 \\
\hline
\end{tabular}

Los hombres pertenecientes a la generación mediana, encuentran históricamente disponibles unos contextos sexuales de sociabilidad o amistad ${ }^{12}$, de ocasionalidad y de pareja no conyugal. Esta generación asiste a la transformación señalada precedentemente y tiene como referencia el cambio operado por las mujeres; por ello, se trata de unos hombres cuyo proceso de iniciación encuentra mujeres en el pasado no disponibles, las pololas y novias. Un 38\% de hombres se inician en el pololeo, un $36 \%$ en el contexto de amistad y un número menor (17\%) en contexto de ocasionalidad sin diferencia entre adscripciones. En la generación más joven, los hombres católicos y no creyentes experimentan una tendencia al aumento de la iniciación en contexto de pololeo (aumenta por sobre diez puntos porcentuales respecto de la generación anterior, se eleva de 38\% a 54\% entre los católicos, y de 37\% a 49\% entre los no creyentes); entre los evangélicos se reduce el contexto marital (pasa de $13 \%$ a $0 \%$ ), que es substituido por el de sociabilidad (46\%) y puede añadirse que entre los últimos, tal como se ve más adelante, la mayor importancia del contexto relacional de pololeo aparece asociado a la mayor observancia. En general, lo anterior parece ubicarse como parte de una reconfiguración de los contextos llamados masculinos entre creyentes y no creyentes, que profundiza el contexto relacional no marital (pololeo), dado, además, que las mujeres se encuentran más disponibles que en el pasado para la iniciación no marital, pero altamente relacional. La observancia, probablemente por razones distintas a las de los no creyentes, intensifica la tendencia seńalada.

12 Sobre este concepto, véase 1. Palma, 2006. 
Como hemos señalado más arriba, se han reconfigurado los contextos de iniciación por parte de las mujeres, un contexto eminentemente marital en la generación antigua ha dado paso en las generaciones siguientes a uno relacional, pero no marital. En la generación mediana, las mujeres pertenecientes a las religiones católica y evangélica, como también las no creyentes, se encuentran próximas en la proporción que hace su entrada en la sexualidad activa en contexto marital (un tercio). A su vez, las mujeres evangélicas no practicantes y practicantes también se encuentran relativamente próximas entre sí (34\% y 39\%) (Véase Tabla № 5). Las mujeres católicas participan de una tendencia que viene de la generación anterior que se orienta a la substitución de la iniciación marital por la iniciación en el pololeo. En esta generación esa orientación impacta más intensamente sobre las no practicantes. Más tarde, en la generación más joven esa distancia se reduce como efecto de un cambio fundamentalmente en las practicantes. Las no practicantes llevan el matrimonio a niveles muy bajos, las practicantes, llegan también a esos mismos bajos niveles, habiéndoles cabido, por tanto, un cambio más intenso. Las mujeres evangélicas han experimentado en la última generación el cambio que de forma general se produjo antes en las otras mujeres practicantes; mantienen su nivel de iniciación marital (38\%), las no practicantes producen una reducción importante $(12 \%)$ y elevan la iniciación en contexto de pololeo $(82 \%)$.

Tabla N $^{\circ}$ 5. ConteXto de INICIACIÓN SEXUAL, SEGÚN ADSCRIPCiÓN Y OBSERVANCIA RELIGIOSA, EDADES Y SEXO (\%) (N: 3532)

\begin{tabular}{|c|c|c|c|c|c|c|c|c|c|c|c|c|c|c|c|c|c|c|c|c|}
\hline & \multicolumn{6}{|c|}{ Católica } & \multicolumn{6}{|c|}{ Evangélica } & \multicolumn{6}{|c|}{ Total } \\
\hline & & & \multicolumn{3}{|c|}{ No practicantes } & \multicolumn{3}{|c|}{ Practicantes } & \multicolumn{3}{|c|}{ No practicantes } & \multicolumn{3}{|c|}{ Practicantes } & \multicolumn{3}{|c|}{ No practicantes } & \multicolumn{3}{|c|}{ Practicantes } \\
\hline & & & M & $\mathrm{H}$ & \begin{tabular}{|l|} 
To- \\
tal
\end{tabular} & $M$ & $\mathrm{H}$ & \begin{tabular}{|c|} 
To- \\
tal
\end{tabular} & $M$ & $\mathrm{H}$ & $\begin{array}{l}\text { To- } \\
\text { tal }\end{array}$ & M & $\mathrm{H}$ & $\begin{array}{l}\text { To- } \\
\text { tal }\end{array}$ & $M$ & $\mathrm{H}$ & $\begin{array}{l}\text { To- } \\
\text { tal }\end{array}$ & $M$ & $\mathrm{H}$ & $\begin{array}{l}\text { To- } \\
\text { tal }\end{array}$ \\
\hline \multirow{6}{*}{$\begin{array}{l}20-29 \\
\text { años }\end{array}$} & $\begin{array}{l}\text { R.conocido } \\
\text { Com. sexual }\end{array}$ & $\%$ & 1 & $\|$ & 6 & 2 & 9 & 5 & 0 & 18 & 10 & 0 & 7 & 3 & 1 & 12 & 7 & 1 & 9 & 4 \\
\hline & Amigo(a) & $\%$ & 5 & 36 & 21 & 3 & 29 & 16 & 6 & 52 & 33 & 0 & 31 & 11 & 5 & 38 & 23 & 2 & 29 & 14 \\
\hline & Esposo(a) & $\%$ & 6 & I & 4 & 5 & I & 3 & 12 & 0 & 5 & 38 & 0 & 25 & 7 & I & 4 & 16 & I & 10 \\
\hline & Pololo(a) & $\%$ & 88 & 51 & 68 & 91 & 61 & 76 & 82 & 28 & 50 & 62 & 62 & 61 & 87 & 48 & 65 & 81 & 61 & 72 \\
\hline & Otro & $\%$ & 0 & I & 1 & 0 & 0 & 0 & 0 & 2 & 1 & 0 & 0 & 0 & 0 & 1 & I & 0 & 0 & 0 \\
\hline & Total & $\%$ & 100 & 100 & 100 & 100 & 100 & 100 & 100 & 100 & 100 & 100 & 100 & 100 & 100 & 100 & 100 & 100 & 100 & 100 \\
\hline \multirow{6}{*}{$\begin{array}{l}30-49 \\
\text { años }\end{array}$} & $\begin{array}{l}\text { R.conocido } \\
\text { Com. sexual }\end{array}$ & $\%$ & 0 & 18 & 10 & 0 & 12 & 4 & I & 21 & 10 & 0 & 13 & 5 & 0 & 19 & 10 & 0 & 12 & 4 \\
\hline & Amigo(a) & $\%$ & 4 & 38 & 22 & 3 & 38 & 14 & 4 & 35 & 18 & I & 23 & 10 & 4 & 38 & 22 & 3 & 34 & 13 \\
\hline & Esposo(a) & $\%$ & 27 & 3 & 14 & 37 & 6 & 28 & 34 & 2 & 20 & 39 & 18 & 31 & 28 & 3 & 15 & 38 & 9 & 29 \\
\hline & Pololo(a) & $\%$ & 68 & 36 & 51 & 59 & 42 & 53 & 61 & 40 & 52 & 59 & 42 & 53 & 67 & 36 & 51 & 59 & 42 & 53 \\
\hline & Otro & $\%$ & 1 & 5 & 3 & 0 & 2 & I & 0 & 1 & 0 & 0 & 4 & 1 & 1 & 4 & 2,51 & 0 & 3 & I \\
\hline & Total & $\%$ & 100 & 100 & 100 & 100 & 100 & 100 & 100 & 100 & 100 & 100 & 100 & 100 & 100 & 100 & 100 & 100 & 100 & 100 \\
\hline
\end{tabular}


Los hombres católicos en la última generación evolucionan en direcciones que presentan una cierta convergencia: practicantes y no practicantes profundizan el contexto de pololeo, el contexto de amistad dice relación al tercio de ellos. Hay una divergencia entre los hombres evangelicos. Los practicantes evangélicos en la última generación presentan una substitución del contexto marital por el de pololeo, y al hacerlo incrementan el contexto relacional no marital, mientras los no practicantes, evolucionan hacia una mayor presencia relativa del contexto de amistad (la mitad de los no practicantes).

En la generación más joven, en la observancia se instala una diferenciación entre las mujeres. Si en las generaciones antiguas existe una mayor homogeneidad en la observancia, en la que ser practicante evangélica tiene gran similitud con ser católica, y ello, a su vez expresaba una mayor conformidad normativa respecto de sus iglesias, asistimos a una diferenciación en las generaciones jóvenes: una practicante evangélica no necesariamente tiene gran similitud con una católica, y ello a su vez expresa una experiencia diferenciada de los sujetos en las instituciones, más individualizada en unas religiones, más comunitariamente subjetivada en otras. En esta generación joven una practicante católica no es asimilable a una evangélica. La primera ha llegado a tener una bajísima iniciación marital (4\%) y la otra mantiene una altísima (38\%), la primera sitúa su iniciación fuertemente en contexto de una pareja no conyugal (91\%), la otra suma en menor medida este último contexto (62\%); así, la primera ha substituido sustantivamente el marido por el pololo, la otra lo hace en menor medida. En la generación más joven un hombre practicante católico es más asimilable a uno evangélico. Uno y otro presentan una ausencia de iniciación marital, situando su iniciación mayoritariamente en contexto de pololeo (61\%, el primero y 62\%, el último), y secundariamente en contexto de amistad (29\%, el primero y $31 \%$, el último).

\section{Reducción y ampliación en el número de parejas sexuales}

Desde las generaciones nacidas en la década de 1950, la sociedad chilena ha experimentado una evolución sistemática hacia trayectorias sexuales femeninas que cursan moderada, pero sistemáticamente hacia la ampliación del número de parejas sexuales en el curso de la vida; esto está asociado a los procesos de ampliación de periodo de sexualidad juvenil (aquel tiempo que transcurre entre la iniciación sexual y la primera unión) y a un aumento progresivo del divorcio, que abre a nuevas parejas sexuales en contextos de post-maritalidad. ${ }^{13}$ La restricción en el número de parejas sexuales deviene obvia cuando se ubican los intercam-

13 Véase: I. Palma, 2006. 
bios sexuales en el contexto marital y este a su vez ha de perdurar toda la vida de un sujeto, aún cuando las orientaciones normativas institucionales se dirijan más fuertemente a las mujeres. ${ }^{14}$

La pertenencia religiosa impacta sobre la restricción y amplitud en el número de parejas sexuales, y lo hace fundamentalmente desde una doble perspectiva: de género y generación (Véase Tabla $\left.\mathrm{N}^{\circ} 6\right) \cdot{ }^{15}$

Tabla Nº 6. NúMERo de PAREJAS SEXUALES EN ÚlTimos CinCo AÑos DE SUJETOS INICIADOS SEXUALMENTE, SEGÚN ADSCRIPCIÓN RELIGIOSA, EDADES Y SEXO (\%) (N: 4I 68)

\begin{tabular}{|c|c|c|c|c|c|c|c|c|c|c|c|c|c|c|}
\hline & \multicolumn{3}{|c|}{ Católica } & \multicolumn{3}{|c|}{ Evangélica } & \multicolumn{3}{|c|}{ Ninguna } & \multicolumn{3}{|c|}{ Total } \\
\hline & & & $M$ & $\mathrm{H}$ & Total & $M$ & $\mathrm{H}$ & Total & M & $\mathrm{H}$ & Total & $M$ & $\mathrm{H}$ & Total \\
\hline \multirow{4}{*}{$20-29$} & Ninguna & $\%$ & 0 & 0 & 0 & 1 & 2 & 2 & 0 & I & 0 & 0 & 1 & 0 \\
\hline & Una & $\%$ & 75 & 27 & 50 & 85 & 51 & 68 & 54 & 32 & 40 & 74 & 31 & 51 \\
\hline & 2 ó más & $\%$ & 25 & 73 & 50 & 14 & 47 & 30 & 46 & 67 & 60 & 26 & 68 & 49 \\
\hline & Total & $\%$ & 100 & 100 & 100 & 100 & 100 & 100 & 100 & 100 & 100 & 100 & 100 & 100 \\
\hline \multirow{4}{*}{$30-49$} & Ninguna & $\%$ & 2 & 1 & 1 & 4 & 0 & 3 & 1 & 0 & I & 2 & 1 & 2 \\
\hline & Una & $\%$ & 90 & 65 & 79 & 88 & 79 & 84 & 81 & 52 & 64 & 89 & 65 & 78 \\
\hline & 2 ó más & $\%$ & 8 & 34 & 20 & 8 & 21 & 13 & 18 & 48 & 35 & 9 & 34 & 20 \\
\hline & Total & $\%$ & 100 & 100 & 100 & 100 & 100 & 100 & 100 & 100 & 100 & 100 & 100 & 100 \\
\hline \multirow{4}{*}{$50-69$} & Ninguna & $\%$ & 31 & 2 & 17 & 30 & 5 & 21 & 26 & 1 & 7 & 30 & 2,46 & 17 \\
\hline & Una & $\%$ & 68 & 78 & 73 & 66 & 82 & 72 & 72 & 60 & 63 & 68 & 77 & 72 \\
\hline & 2 ó más & $\%$ & I & 20 & 10 & 4 & 13 & 7 & 2 & 39 & 30 & 2 & 21 & 11 \\
\hline & Total & $\%$ & 100 & 100 & 100 & 100 & 100 & 100 & 100 & 100 & 100 & 100 & 100 & 100 \\
\hline \multirow{4}{*}{ Total } & Ninguna & $\%$ & 9 & 1 & 5 & 10 & 2 & 7 & 3 & 1 & 2 & 8 & 1 & 5 \\
\hline & Una & $\%$ & 81 & 58 & 70 & 82 & 70 & 77 & 69 & 44 & 53 & 81 & 58 & 70 \\
\hline & 2 ó más & $\%$ & 10 & 41 & 25 & 8 & 28 & 16 & 28 & 55 & 46 & 11 & 41 & 25 \\
\hline & Total & $\%$ & 100 & 100 & 100 & 100 & 100 & 100 & 100 & 100 & 100 & 100 & 100 & 100 \\
\hline
\end{tabular}

En todos los grupos estudiados, los no creyentes presentan los mayores niveles de parejas sexuales y los evangélicos, los más bajos. En la generación mayor, las diferencias son fundamentalmente de género, fuertemente conectadas a la estructuración social de las edades y del sexo. En este grupo existe una brecha a favor de los hombres en el número de parejas, como consecuencia de procesos de continuidad y cesación de la vida sexual activa debidos a la estructuración social de las edades, la esperanza de vida y a los contextos sexuales prescritos para hombres y mujeres en esas edades y generaciones. Lo abordamos de este modo, observando a

14 Recuérdese aquí la recientemente modificada norma legal sobre el adulterio.

15 Analizamos aquí el número de parejas sexuales en el curso de los últimos cinco años en los grupos mayores (50-69 años), de edades medianas (35-49 años) y más joven (20-29 años), de modo de compararles en una trayectoria en cuyo comienzo y término existen menos sujetos activos. 
los sujetos situados en los extremos: los que no tienen pareja sexual y aquellos que tienen dos o más. Así, se encuentran sin pareja sexual un 31\% de mujeres católicas, 30\% de evangélicas, $26 \%$ de no creyentes, 2\% de hombres católicos, 5\% de evangélicos y $1 \%$ de no creyentes; declaran dos o más parejas sexuales un $1 \%$ de católicas, 4\% de evangélicas, 2\% de mujeres no creyentes, 19\% de católicos, 13\% de evangélicos y $38 \%$ de hombres no creyentes. Puede colegirse de lo anterior que las restricciones son comunes a las mujeres, independientemente de su pertenencia, del mismo modo que entre los hombres, quienes no profesan religión tienen una más alta proporción de sujetos con mayor número de parejas sexuales.

En el grupo de edades medianas se amplía el número de parejas sexuales, desplazándose la diferencia entre hombres y mujeres; si antes el punto de partida era la ausencia de pareja sexual, ahora es al menos una pareja, ${ }^{16}$ por tanto la diferencia se ubica en la proporción de mujeres y hombres que declaran dos o más parejas sexuales. Se observan dos elementos notables: el mayor aumento entre las mujeres no creyentes (18\%, cuando las católicas y evangélicas alcanzan a $8 \%$ ) y el menor aumento entre los hombres evangélicos $(21 \%$, cuando los católicos alcanzan a $34 \%$ y no creyentes a $48 \%$ ).

Lo anterior sugiere la instalación de una diferencia en las generaciones recientes que concierne al mismo tiempo al género y a la pertenencia religiosa. Efectivamente, en la generación joven se incrementa de forma muy importante el número de parejas sexuales (un 48\% declara dos o más, cuando en la generación más antigua es $11 \%$, y en la mediana, 20\%). En esta generación se profundiza un desfase entre las no creyentes y las otras, muy especialmente respecto de las evangélicas (46\% declara dos o más parejas, cuando las católicas declaran 25\% y las evangélicas, 14\%). Al mismo tiempo, los hombres evangélicos profundizan también su desfase respecto de los otros hombres, lo que los deja más rezagados (47\% declara dos o más parejas, cuando los católicos declaran 73\% y los no creyentes, 67\%). En su conjunto, hombres y mujeres evangélicos se distancian de las otras adscripciones.

La observancia, como vemos a continuación, sugiere la instalación de una diferencia en las generaciones recientes que hace al mismo tiempo al género y a la pertenencia religiosa (Véase Tabla $\mathrm{N}^{\circ} 7$ ). Existe gran similitud en las mujeres mayores entre practicantes y no practicantes, y entre una y otra pertenencia religiosa. En el grupo de edades medianas, se introduce una diferencia en el paso a dos o más parejas. Allí, un grupo relativamente pequeño de mujeres no practicantes, católicas y evangélicas, incrementa el número respecto de la generación anterior,

16 Declaran ninguna pareja sexual en el curso de los últimos cinco años un 2,05\% de católicas, $4,31 \%$ de evangélicas y $1,25 \%$ de mujeres no creyentes. 
quedando desfasadas las practicantes, levemente en el caso de las católicas, un poco más intensamente en las evangélicas. En la generación joven, las católicas -practicantes y no practicantes- y las evangélicas no practicantes introducen una inflexión mayor en el número de parejas (a pesar de una trayectoria más corta que la de los otros grupos de edades) y con ello se produce una diferenciación muy importante respecto de las jóvenes evangélicas practicantes.

Tabla $\mathbf{N}^{\circ}$ 7. Número de PAREJAS SEXUALES EN ÚlTimos CiNCO AÑOS DE SUJETOS INICIADOS SEXUALMENTE, SEGÚN ADSCRIPCIÓN Y OBSERVANCIA RELIGIOSA, EDADES Y SEXO (\%) (N: 4I 68)

\begin{tabular}{|c|c|c|c|c|c|c|c|c|c|c|c|c|c|c|c|c|c|c|c|c|}
\hline & \multicolumn{6}{|c|}{ Católica } & \multicolumn{6}{|c|}{ Evangélica } & \multicolumn{6}{|c|}{ Total } \\
\hline & & & \multicolumn{3}{|c|}{ No practicantes } & \multicolumn{3}{|c|}{ Practicantes } & \multicolumn{3}{|c|}{ No practicantes } & \multicolumn{3}{|c|}{ Practicantes } & \multicolumn{3}{|c|}{ No practicantes } & \multicolumn{3}{|c|}{ Practicantes } \\
\hline & & & M & $\mathrm{H}$ & $\begin{array}{l}\text { To- } \\
\text { tal }\end{array}$ & M & $\mathrm{H}$ & $\begin{array}{l}\text { To- } \\
\text { tal }\end{array}$ & $M$ & $H$ & $\begin{array}{l}\text { To- } \\
\text { tal }\end{array}$ & M & $\mathrm{H}$ & $\begin{array}{l}\text { To- } \\
\text { tal }\end{array}$ & $M$ & $\mathrm{H}$ & $\begin{array}{l}\text { To- } \\
\text { tal }\end{array}$ & $M$ & $\mathrm{H}$ & $\begin{array}{l}\text { To- } \\
\text { tal }\end{array}$ \\
\hline \multirow{4}{*}{ 20-29 } & Ninguna & $\%$ & 0 & I & 0 & 0 & 0 & 0 & 0 & 0 & 0 & 2 & 7 & 4 & 0 & I & 0 & I & 2 & I \\
\hline & Una & $\%$ & 75 & 29 & 51 & 74 & 20 & 49 & 77 & 48 & 60 & 93 & 61 & 82 & 75 & 32 & 52 & 80 & 30 & 59 \\
\hline & 2 ó más & $\%$ & 25 & 70 & 49 & 26 & 80 & 51 & 23 & 52 & 40 & 5 & 32 & 14 & 25 & 67 & 48 & 19 & 68 & 40 \\
\hline & Total & $\%$ & 100 & 100 & 100 & 100 & 100 & 100 & 100 & 100 & 100 & 100 & 100 & 100 & 100 & 100 & 100 & 100 & 100 & 100 \\
\hline \multirow{4}{*}{$30-49$} & Ninguna & $\%$ & 2 & 2 & 2 & 2 & 0 & 1 & 0 & 0 & 0 & 7 & 0 & 4 & 2 & 1 & 2 & 3 & 0 & 2 \\
\hline & \begin{tabular}{|l|} 
Una \\
\end{tabular} & $\%$ & 88 & 58 & 72 & 92 & 79 & 88 & 88 & 73 & 81 & 91 & 83 & 88 & 88 & 60 & 73 & 91 & 80 & 88 \\
\hline & 2 ó más & $\%$ & 10 & 40 & 26 & 7 & 21 & 11 & 12 & 27 & 19 & 2 & 17 & 8 & 10 & 39 & 25 & 6 & 20 & 10 \\
\hline & Total & $\%$ & 100 & 100 & 100 & 100 & 100 & 100 & 100 & 100 & 100 & 100 & 100 & 100 & 100 & 100 & 100 & 100 & 100 & 100 \\
\hline \multirow{4}{*}{$50-69$} & Ninguna & $\%$ & 29 & 2 & 14 & 32 & 3 & 20 & 36 & 3 & 22 & 28 & 6 & 21 & 30 & 2 & 15 & 31 & 3 & 20 \\
\hline & \begin{tabular}{|l|} 
Una \\
\end{tabular} & $\%$ & 69 & 77 & 73 & 67 & 79 & 72 & 64 & 74 & 68 & 67 & 86 & 73 & 68 & 77 & 73 & 67 & 80 & 72 \\
\hline & 2 ó más & $\%$ & 2 & 21 & 13 & 1 & 18 & 8 & 0 & 23 & 10 & 5 & 8 & 6 & 2 & 21 & 12 & 2 & 17 & 8 \\
\hline & Total & $\%$ & 100 & 100 & 100 & 100 & 100 & 100 & 100 & 100 & 100 & 100 & 100 & 100 & 100 & 100 & 100 & 100 & 100 & 100 \\
\hline
\end{tabular}

En los hombres mayores, por su parte, los católicos -practicantes y no practicantes- $\mathrm{y}$ los evangélicos no practicantes presentan gran similitud en niveles más elevados de parejas sexuales que los evangélicos practicantes. En el grupo de edades medianas se produce un distanciamiento en el paso a dos o más parejas entre los hombres católicos no practicantes (40\%), en el otro extremos los evangélicos practicantes (17\%), en el medio se encuentran católicos practicantes (20\%) y evangélicos no practicantes. (27\%). Por su parte, en la generación más joven los hombres católicos incrementan su nivel hacia dos o más pareja, más intensamente los practicantes que los no practicantes, quedando éstos en esta generación muy próximos entre sí (80\% y 70\%, respectivamente). También los evangélicos incrementan sus niveles respecto de la generación anterior de dos o más pareja, más intensamente entre los no practicantes que en los practicantes (52\% y $32 \%$, respectivamente), manteniendo una brecha entre sí. 


\section{Restricción y plasticidad de las prácticas sexuales}

Una de las transformaciones producidas en contexto de modernidad se ubica en el ámbito de las prácticas sexuales. Estas se han vuelto más plásticas en sus sentidos, contextos y formas, en una condición de separación eficiente de la reproducción y la sexualidad, ${ }^{17}$ en la superación de una alta especialización contextual de las prácticas (en el pasado, sexo anal en comercio sexual, sexo vaginal en el matrimonio), en que la sexualidad se ha vuelto motor de las relaciones de pareja, su calidad se encuentra subjetiva y discursivamente asociada a su mantención. Esto opera como expansión de los repertorios sexuales..$^{18}$ La proscripción de prácticas no vaginales constituye una norma sexual de las religiones cristianas, en especial, la práctica de sexo anal, independientemente de no ser realizada entre hombres, remite aún en las representaciones sociales a actos viciosos y pecaminosos, tradicionalmente no sólo prohibidos por no reproductivos y considerados "antinaturales" en relación al objeto y/o a la forma de relación con el mismo.

Las adscripciones religiosas presentan diferencias en sus prácticas sexuales (Véase Tabla $\mathrm{N}^{\circ}$ 8). ${ }^{19}$ Observados los tres grupos de edades, en general católicos y no creyentes presentan una proporción baja pero más elevada de repertorio amplio, en un contexto en que las prácticas restringidas son dominantes (85\% en el grupo de edades mayores, $66 \%$ en el siguiente y $55 \%$ en el más joven. El grupo de hombres y mujeres mayores presenta un repertorio altamente restringido, similar entre católicos y no creyentes ( $84 \%$ y $83 \%$, respectivamente) y más alto entre los evangélicos (93\%). En el grupo de edades medianas se reduce en

17 Véase: A. Giddens, 1995. La Transformación de la Intimidad. Sexualidad, Amor y Erotismo en las Sociedades Modernas. Ediciones Cátedra. Madrid.

18 Puede sugerirse analíticamente la operación de ciertos patrones de comportamiento sexual en los cuales se inscriben las prácticas concretas. En primer lugar, la presencia de un patrón caracterizado por la exclusividad de la práctica vaginal, que denominamos "repertorio sexual restringido". En segundo lugar, se sugiere la presencia de un patrón que hemos denominado "repertorio sexual amplio", basado en la combinación de la práctica vaginal con las formas oral y anal. Asimismo, puede sugerirse la existencia al interior del último patrón de dos modalidades específicas y progresivas: una primera forma que incorpora sexo oral a las prácticas sexuales, y una segunda forma que, una vez integrada la anterior, incorpora sexo anal. La distinción resulta pertinente por cuanto los niveles de frecuencia alcanzados por ambas formas varían, pero sobre todo porque respecto de las prácticas sexuales expresan fenómenos diferentes. La primera presenta un alto nivel de frecuencia y parece integrarse bajo una lógica de normalización de ciertas prácticas sexuales: el sexo oral se transforma en el preámbulo de la forma vaginal que le sucede. La última, en cambio, aparece menos frecuente y se presenta básicamente como ańadida a la anterior y casi siempre la supone, aunque presenta también su propia especificidad. La práctica que incluye sexo anal se constituye propiamente en variación en el ámbito de las prácticas sexuales.

19 Analizamos aquí la última relación sexual en los tres grupos etarios. 
todas las adscripciones presencia del repertorio restringido, la mayor reducción la producen los no creyentes (60\%, cuando católicos alcanzan a 66\% y evangélicos a $72 \%$ ). En el grupo más joven continúa su reducción, católicos y no creyentes bajan a 52\% y 58\%, y evangélicos, que descienden igual que los otros, diez puntos, quedan en $63 \%$.

Tabla Nº 8. Prácticas seXuales en CONTEXTo de la Última Relación SEXUAL CON ÚLTIMA PAREJA SEXUAL, SEGÚN ADSCRIPCIÓN RELIGIOSA, EDADES Y SEXO (\%) (N: 3 I 55 )

\begin{tabular}{|c|c|c|c|c|c|c|c|c|c|c|c|c|c|c|}
\hline & \multicolumn{3}{|c|}{ Católica } & \multirow[b]{2}{*}{ M } & \multirow[b]{2}{*}{$\mathrm{H}$} & \multirow[b]{2}{*}{ Total } & \multicolumn{3}{|c|}{ Ninguna } & \multicolumn{3}{|c|}{ Total } \\
\hline & & & $M$ & $\mathrm{H}$ & Total & & & & M & $\mathrm{H}$ & Total & M & $\mathrm{H}$ & Total \\
\hline \multirow{3}{*}{$20-29$} & Restringido & $\%$ & 59 & 47 & 52 & 78 & 48 & 63 & 67 & 52 & 58 & 63 & 48 & 55 \\
\hline & Ampliado & $\%$ & 41 & 53 & 48 & 22 & 52 & 37 & 33 & 48 & 42 & 37 & 52 & 45 \\
\hline & Total & $\%$ & 100 & 100 & 100 & 100 & 100 & 100 & 100 & 100 & 100 & 100 & 100 & 100 \\
\hline \multirow{3}{*}{$30-49$} & Restringido & $\%$ & 69 & 62 & 66 & 76 & 67 & 72 & 66 & 55 & 60 & 70 & 62 & 66 \\
\hline & Ampliado & $\%$ & 31 & 38 & 34 & 24 & 33 & 28 & 34 & 45 & 40 & 30 & 38 & 34 \\
\hline & Total & $\%$ & 100 & 100 & 100 & 100 & 100 & 100 & 100 & 100 & 100 & 100 & 100 & 100 \\
\hline \multirow{3}{*}{$50-69$} & Restringido & $\%$ & 88 & 81 & 84 & 94 & 92 & 93 & 98 & 81 & 83 & 90 & 82 & 85 \\
\hline & Ampliado & $\%$ & 12 & 19 & 16 & 6 & 8 & 7 & 2 & 19 & 17 & 10 & 18 & 15 \\
\hline & Total & $\%$ & 100 & 100 & 100 & 100 & 100 & 100 & 100 & 100 & 100 & 100 & 100 & 100 \\
\hline
\end{tabular}

Mujeres y hombres presentan diferencias en cada una de las adscripciones, en favor de los hombres. En el grupo más adulto, las mayores diferencias se presentan en no creyentes (un 98\% de mujeres declara un repertorio restringido y un $81 \%$ de hombres). En la generación siguiente todos, hombres y mujeres, han incrementado moderadamente el repertorio ampliado; los católicos se diferencian internamente menos (un 69\% de mujeres declara un repertorio restringido y un $62 \%$ de hombres), los no creyentes mucho más (un 66\% de mujeres declara un repertorio restringido y un $54 \%$ de hombres). En la generación más joven desciende de forma importante la presencia del repertorio restringido y en hombres evangélicos. Las diferencias se acortan entre católicos (12 puntos porcentuales separan a hombres y mujeres), tienden a mantenerse entre no creyentes y se ensanchan entre evangélicos (30 puntos porcentuales separan a hombres y mujeres). Las diferencias entre mujeres aumentan en el curso de las generaciones debido a un descenso del repertorio restringido operado por las católicas, especialmente. Los hombres cambian todos, hasta alcanzar en la última generación niveles inferiores al cincuenta por ciento 
Tabla Nº 9. Prácticas sexuales en Contexto de Última Relación SEXUAL CON ÚLTIMA PAREJA SEXUAL, SEGÚN ADSCRIPCIÓN Y OBSERVANCIA RELIGIOSA, EDADES Y SEXO (\%) (N: 3 I 55 )

\begin{tabular}{|c|c|c|c|c|c|c|c|c|c|c|c|c|c|c|c|c|c|c|c|c|}
\hline & \multicolumn{6}{|c|}{ Católica } & \multicolumn{6}{|c|}{ Evangélica } & \multicolumn{6}{|c|}{ Total } \\
\hline & & & \multicolumn{3}{|c|}{$\begin{array}{l}\text { No practi- } \\
\text { cantes }\end{array}$} & \multicolumn{3}{|c|}{ Practicantes } & \multicolumn{3}{|c|}{$\begin{array}{l}\text { No practi- } \\
\text { cantes }\end{array}$} & \multicolumn{3}{|c|}{ Practicantes } & \multicolumn{3}{|c|}{$\begin{array}{l}\text { No practi- } \\
\text { cantes }\end{array}$} & \multicolumn{3}{|c|}{ Practicantes } \\
\hline & & & M & $\mathrm{H}$ & \begin{tabular}{|l} 
To- \\
tal \\
\end{tabular} & $M$ & H & $\begin{array}{l}\text { To- } \\
\text { tal }\end{array}$ & $M$ & H & \begin{tabular}{|l|} 
To- \\
tal \\
\end{tabular} & M & $\mathrm{H}$ & $\begin{array}{l}\text { To- } \\
\text { tal }\end{array}$ & M & H & \begin{tabular}{|l|} 
To- \\
tal \\
\end{tabular} & M & $\mathrm{H}$ & $\begin{array}{l}\text { To- } \\
\text { tal }\end{array}$ \\
\hline \multirow{3}{*}{ 20-29 } & Restringido & $\%$ & 58 & 42 & 49 & 62 & 57 & 59 & 74 & 40 & 54 & 82 & 68 & 78 & 60 & 42 & 50 & 69 & 59 & 65 \\
\hline & Ampliado & $\%$ & 42 & 58 & 51 & 38 & 43 & 41 & 26 & 60 & 46 & 18 & 32 & 22 & 40 & 58 & 50 & 30 & 41 & 35 \\
\hline & Total & $\%$ & 100 & 100 & 100 & 100 & 100 & 100 & 100 & 100 & 100 & 100 & 100 & 100 & 100 & 100 & 100 & 100 & 100 & 100 \\
\hline \multirow{3}{*}{$30-49$} & Restringido & $\%$ & 66 & 61 & 63 & 72 & 64 & 69 & 80 & 64 & 73 & 73 & 70 & 71 & 68 & 61 & 64 & 72 & 66 & 70 \\
\hline & Ampliado & $\%$ & 34 & 39 & 37 & 28 & 36 & 31 & 20 & 36 & 27 & 27 & 30 & 29 & 32 & 39 & 36 & 28 & 34 & 30 \\
\hline & Total & $\%$ & 100 & 100 & 100 & 100 & 100 & 100 & 100 & 100 & 100 & 100 & 100 & 100 & 100 & 100 & 100 & 100 & 100 & 100 \\
\hline \multirow{3}{*}{$50-69$} & Restringido & $\%$ & 95 & 83 & 86 & 84 & 81 & 82 & 93 & 87 & 90 & 94 & 94 & 94 & 95 & 83 & 87 & 86 & 83 & 85 \\
\hline & Ampliado & $\%$ & 5 & 17 & 14 & 16 & 19 & 18 & 7 & 13 & 10 & 6 & 6 & 6 & 5 & 17 & 13 & 14 & 17 & 15 \\
\hline & Total & $\%$ & 100 & 100 & 100 & 100 & 100 & 100 & 100 & 100 & 100 & 100 & 100 & 100 & 100 & 100 & 100 & 100 & 100 & 100 \\
\hline
\end{tabular}

En el grupo de edades medianas, una mujer practicante católica, por el contrario, es asimilable a una evangélica. Una y otra comparten niveles similares de apropiación de un repertorio restringido ( $72 \%$ y $73 \%$, respectivamente). También lo es un hombre practicante católico respecto de uno evangélico. Uno y otro comparten niveles similares de apropiación de un repertorio restringido (64\% y $70 \%$, respectivamente). En tanto, en el grupo de jóvenes una practicante católica no es asimilable a una evangélica. La primera pone en acción en una proporción menor que la otra un repertorio restringido ( $58 \%$ y $74 \%$, respectivamente). Tampoco lo es un joven practicante católico respecto de uno evangélico. El primero pone en acción en una proporción menor que el otro un repertorio restringido ( $57 \%$ y $70 \%$, respectivamente).

\section{Interpretación de los datos del estudio}

Los datos presentados precedentemente requieren de un análisis contextualizado. Sobre todo, nos interesa comprender qué está detrás de la observancia religiosa y dónde reside su capacidad normativa en el campo de la sexualidad.

\section{La transformación normativa en la sociedad chilena: orienta- ciones normativas, sistema de soporte de la norma, relación entre sujetos e instituciones}

Tanto la sexualidad como la religión han cambiado y están cambiando en la sociedad chilena; ambas se encuentran en la transformación normativa. 
Sugerimos que esto ha de ser observado en un conjunto de planos: transformación en las orientaciones normativas, del sistema de soporte de la norma, reconfiguración de la relación entre el sujeto y las instituciones normativas, y relaciones entre instituciones normativas.

En primer lugar, es manifiesta la existencia de un proceso en curso de transformaciones en las orientaciones normativas respecto de la sexualidad. Dichas transformaciones no se limitan a la sociedad chilena sino que son parte de cambios más globales, que involucran a la política, a la cultura, a la escolaridad, a las comunicaciones, a la generalización del uso cotidiano de tecnologías de punta (internet, computadores, máquinas domésticas, etc.) y, no menos influyente, a la generalización del mercado en los intercambios entre individuos. Por cierto, se trata de cambios que no son homogéneos, ni generalizados como tampoco presentan orientaciones únicas (el sentido mismo del cambio es debatible).

En segundo lugar, el sistema mismo de la institucionalidad que propone o que sostiene la norma se ha modificado; esto es, la presencia simultánea de múltiples instituciones dotadas de legitimidades particulares (religiosas, médicas, legales, demográficas, políticas, culturales, nacionales e internacionales), pone en cuestión el reconocimiento de alguna de ellas como institución exclusiva con capacidad normativa, es decir, con capacidad para proponer la norma y demandar su realización. En general, la homogeneidad estructural, institucional y normativa da paso a la heterogeneidad. Existe una proliferación de normas y de instituciones y agentes con capacidad para operar en el ámbito de los discursos públicos y, con más dificultad, en los sistemas de controles públicos y privados. Las instituciones y agencias constituyen más bien fuentes productoras de discursos normativos que de sistemas de control; incluso uno de los sistemas más clásicos de la institucionalidad católica, la confesión, perdió su capacidad de control sobre sus fieles.

En otras palabras, el sistema institucional y normativo de la sexualidad se ha diversificado y se ha vuelto heterogéneo y en muchos sentidos contradictorio. La formulación normativa de una institución enfrenta una alta probabilidad de colisionar con las formulaciones normativas propuestas por otras instituciones. Con frecuencia, las propuestas normativas de una institución aparecen crecientemente contestadas por las propuestas de otras instituciones, construidas en referencia a otras fuentes de legitimación y autoridad: la religión, la ética, las ciencias biomédicas, las ciencias sociales, los movimientos y colectivos sociales. ${ }^{20}$

20 Puede recordarse aquí el debate sobre la introducción de la anticoncepción de emergencia en el país. La medicina y la Iglesia Católica ofrecieron ambas argumentaciones al mismo tiempo científicas y éticas. 
En tercer lugar, si la norma está confrontada a persuadir a los individuos, las instituciones normativas están confrontadas a incrementar su eficacia en la sociedad, de modo de poder efectivamente influir sobre ella; en la sociedad contemporánea, ninguna de ellas, de manera aislada, aparece provista de la capacidad para hacerlo, salvo de manera limitada. Se reconfiguran, entonces, las relaciones entre instituciones; éstas buscan influirse mutuamente, de modo de lograr que sus propuestas normativas sean adoptadas o representadas por las otras. El campo en que ello se realiza es el de la relación con el Estado, es decir, el poder para transformar la norma en ley (la norma puede transgredirse sin que necesariamente tenga costos, la ley no). Por ello, tanto las instituciones religiosas como las instituciones médicas, científicas, culturales o sociales se dirigen activamente al Estado, procurando que sus orientaciones normativas sean reconocidas en la legislación, operando prescriptiva o proscriptivamente (por ejemplo, la disputa legal por la "píldora del día después").

En cuarto lugar, se han reconfigurado las relaciones entre el sujeto y las instituciones normativas; más que con un carácter prescriptivo o proscriptivo, la institución tiende a reducir su capacidad de control y tiende a un carácter más bien indicativo, es decir, la norma tiene que explicarse o justificarse a sí misma frente a los individuos, tiene que convencerlos, seducirlos, parecer racional, ser biográficamente productiva. Su valor radica en que sea inteligible, viable y útil para el individuo; éste requiere hacer sentido de la norma, interpretarla, adaptarla a sus requerimientos biográficos, vivirla socialmente en la relación con el mundo. En este sentido, en general, el individuo cobra autonomía respecto de las instituciones normativas, está confrontado a discernir reflexivamente la norma en la diversidad de situaciones que le toca vivir cotidianamente, hacerse cargo de sus decisiones. No obstante, es posible distinguir dos modalidades de respuestas de los individuos a la socialización normativa de las instituciones religiosas. Por un lado, la individualización, es decir, el individuo está confrontado a un quehacer reflexivo personal, singular y situacional en relación a sus valores, sus comportamientos, sus normas. Por otro lado, la subjetivación comunitaria, es decir, el individuo reconoce pertenencia e identificación con una comunidad religiosa que le demanda consistencia comportamental entre el decir y el hacer, entre discurso y práctica.

\section{Religión, comunidad y trayectorias religiosas}

La religión católica se ubica como parte de la tradición social y cultural e, históricamente, la adscripción a ella ha operado como religión heredada. Las otras religiones, principalmente la religión evangélica, han debido instalarse y desarrollarse en una sociedad que a comienzos del siglo XX aparecía casi enteramente católica. En las primeras décadas de dicho siglo emergen las iglesias pentecostales, 
en una gran diversidad de formas organizacionales, doctrinarias y de ubicaciones sociales. ${ }^{21}$ También surgen corrientes laicas que se extienden en la sociedad, especialmente asociadas al desarrollo del movimiento obrero y los partidos políticos de izquierda. En la actualidad, la población chilena se declara mayoritariamente católica, especialmente las mujeres, quienes profesan esa religión en el $72 \%$ de los casos y los hombres en el 68\%. Le sigue en importancia numérica la religión evangélica, con el 16\% de las mujeres y el 14\% de los hombres. La tendencia registrada por los Censos de 1992 y 2002 muestra una disminución relativa de los católicos para mujeres y hombres, y un aumento relativo de la población evangélica y de la que no profesa religión. ${ }^{22}$

Por ello, las religiones emergentes han tenido también un fuerte carácter comunitario y, en muchos sentidos, intensamente testimonial (Palma, S. 1996). Esto se expresa en que dichas religiones presentan también una fuerte observancia (aún cuando, como en el caso de la religión evangélica, ésta tiende a disminuir a medida que se incrementa su adscripción por herencia familiar). Un estudio realizado en la década de los noventa (Fontaine, 1991) sugiere que la observancia religiosa activa, expresada a través de la frecuencia semanal de asistencia a servicios religiosos, muestra una tendencia decreciente, especialmente al interior de la opción "evangélica”. Respecto de esta última, también resulta notoria su tendencia a la reproducción (64.9\% de sus miembros proviene de familias cuya religión de origen es evangélica), en circunstancias que desde sus orígenes su gran fuente de expansión estuvo dada por el catolicismo (Canales, Palma y Villela, 1990). Esto último ocurre en un contexto de procesos de movilidad religiosa operados en la sociedad chilena en las décadas pasadas. ${ }^{23}$

21 En Chile, el término "evangélico" se usa de manera general para designar todas aquellas confesiones e instituciones religiosas cristianas distintas del catolicismo y que comparten, en general, los principios de la Reforma Protestante europea. En este sentido, opera más como una denominación compartida y auto asignada que como una distinción de carácter histórico, institucional o doctrinal (Lalive D’Epinay, 1968; Canales et al. 1991). CENSOS 1992-2002, INE. Población mayor de 14 años por religión que profesa.

23 En la Encuesta CONASIDA/ANRS aquí analizada, las religiones de origen -o su ausencia en las familias de origen (religión en la que nació)- respecto de las adscripciones actuales presentan continuidades y discontinuidades. Lo católico de origen muestra, al mismo tiempo, continuidad y derivación: por un lado, la adscripción católica actual en un altísimo nivel refiere a un origen católico (98.1\%); por otro, está en el origen de las adscripciones no católicas en grados diversos: $59.3 \%$ entre laicos, $39.2 \%$ en la categoría otra, y $30.4 \%$ en la adscripción evangélica. Por su parte, lo evangélico muestra un alto nivel de reproducción interna (64.9\% de adscripción proviene de la misma religión), deriva de lo católico en un $30.4 \%$, y a su vez, produce escasa derivación a otras religiones; aporta más al grupo sin religión (14.7\%). La adscripción a la categoría otra religión se conforma en un $50 \%$ por un origen similar, y en el resto de forma importante por el catolicismo (39.2\%). La opción sin religión tiene un origen fundamentalmente religioso, mayoritariamente católico (59.3\%); sólo un $21.3 \%$ tiene un origen laico. 
Este doble movimiento de reducción de la observancia activa (general para todas las religiones) y de predominio de una tendencia a la reproducción de la religión de origen de los padres (caso de evangélicos), puede sugerir la emergencia de una creciente individualización religiosa, en el sentido de que ya no es la institución familiar la que socializa en una religión y la hereda a sus miembros, sino que las opciones religiosas son crecientemente producidas por las personas. En otras palabras, es posible escoger la religión; se puede mantener o no la religión de los padres; se puede elegir tener o no tener religión, mantenerse en la de origen o pasar a otra; se puede elegir tener alta o baja religiosidad, es decir tener una religión de forma más o menos intensa. Existen propiamente trayectorias religiosas ${ }^{24}$ que se modifican en el tiempo; respecto de éstas puede sugerirse, a su vez, la existencia de una alta movilidad al interior de las comunidades evangélicas (tránsito de una comunidad evangélica a otra).

Como hemos afirmado antes, los datos analizados sugieren una diferencia al interior de la "observancia religiosa" entre individuos de adscripción católica y evangélica; particularmente, las mujeres evangélicas muestran una estrecha asociación entre observancia y sujeción a la norma sexual de las instituciones religiosas. En este último caso, puede afirmarse que la cercanía con la institucionalidad y la autoridad religiosa refuerzan la normatividad acerca de la sexualidad, al ubicarse los individuos bajo un campo de observación o de control en que la institucionalidad y la autoridad religiosa pueden efectivamente hacerles saber lo que esperan de ellos y ellas y señalarles las desviaciones de la norma, en caso de ocurrir. No obstante, también es posible sugerir, desde la perspectiva de los individuos, que éstos encuentran en la institución religiosa la posibilidad de ser parte de una comunidad de pertenencia, con la cual identificarse y con la cual, también, construir acuerdos normativos propios, aunque congruentes con los de la institucionalidad y la autoridad religiosa. Se trata, por tanto, de una modalidad de subjetivación que responde a la socialización normativa religiosa.

24 Tuirán sugiere un uso del concepto de trayectoria en relación a la experiencia vital que transcurre en un doble vínculo entre procesos estructurales e historias personales y familiares. Contribuye por su posibilidad de producir una concatenación entre las dimensiones interiores y exteriores a los sujetos (Heilborn et al., 2006). Según Bourdieu (1988), toda trayectoria social debe ser comprendida como una manera singular de recorrer el espacio social. Sin embargo, cada posición tomada en el campo es una exclusión de otras posiciones, por lo que a medida que se recorre el espacio social, se da un envejecimiento social, una imposibilidad de volver atrás, de variar. Los actores recorren a lo largo de sus vidas un continuo de experiencias que van trazando itinerarios -a veces más previsibles, a veces más aleatorios- que se construyen simultánea y pluralmente en múltiples dimensiones: familiar, social, laboral, política, religiosa, cultural. Godard sostiene: "Un individuo no es una historia. Se constituye como tal a partir de varias historias. Cada individuo es por lo menos cuatro historias: historia residencial, historia familiar, historia de formación e historia profesional.” (1996, p. 18). 
Así, puede asumirse que la intensidad y frecuencia de la participación en actividades religiosas (concurrencia de una o más veces por semana), más que descansar sobre prescripciones institucionales, se soporta sobre un sentido, expreso o tácito, de pertenencia e identificación con una comunidad religiosa local o, más precisamente, de subjetivación comunitaria. Puede también asumirse que tanto el sentido de pertenencia como el sentido de identificación con una comunidad religiosa local, se sustentan, a su vez, sobre una demanda de congruencia y consistencia entre discurso y práctica o entre el decir y el hacer. En este sentido, una comunidad de este tipo demanda a sus miembros estilos de comportamiento específicos, los cuales pueden ser enunciados como "testimonio" o "estilo comportamental testimonial". A su vez, dicho estilo comportamental testimonial puede ser observado como una manifestación de algo que le subyace. Siguiendo a Moscovici (1981), puede sugerirse que dicho estilo es propio de las minorías activas, es decir, aquellas que siendo tales se proponen influir sobre la mayoría a través de mostrarse a sí mismas en la consistencia de sus comportamientos, es decir, en la congruencia entre el decir y el hacer; ahí radicaría su fuerza y su capacidad de influencia.

En la medida en que la religión, cualquiera sea, opera sobre la base de expresar una "verdad" que el mundo debe conocer, reconocer, aceptar y orientarse por ella, el comportamiento testimonial cumple también la función de representar esa verdad y dar testimonio, de palabra y de acción, acerca de ella. Por ello, puede considerarse que un grupo o una comunidad religiosa de observancia y participación intensa, operan efectivamente como una minoría que se propone, expresa o tácitamente, influir sobre el conjunto de la sociedad a través del testimonio personal y grupal o comunitario. Por ello también, puede considerarse que, más que una referencia a la institución religiosa, en general, el testimonio personal y grupal o comunitario aparece, propiamente, como una construcción del propio grupo, como una subjetivación comunitaria (una misma institucionalidad religiosa puede contener grupos minoritarios activos, así como también grupos pasivos, no minoritarios, que adscriben en muchos sentidos a la mayoría o a la sociedad).

La situación anterior puede ser referida tanto a los grupos minoritarios católicos como a los evangélicos. En realidad, estos últimos han sido, especialmente en sus orígenes, intensamente minoritarios; esto es, sus estrategias de instalación y desarrollo en la sociedad chilena descansaban fuertemente sobre estilos de comportamiento testimoniales: un individuo se presentaba a sí mismo como expresión del cambio que la comunidad religiosa podía proveer a cualquier miembro de la mayoría (en el caso de los grupos más pobres de la sociedad, como un cambio deseable para cualquiera). Por ello, un elemento importante a observar será la capacidad de una religión para producir la socialización de los individuos o, expresado 
en otros términos, para constituir comunidades de lenguaje y de experiencia, es decir, para producir en los individuos una subjetivación correspondiente.

\section{Conclusiones}

Hemos formulado una distinción entre adscripción y observancia religiosa, en el contexto de una sociedad crecientemente secularizada. Tal distinción nos ha permitido establecer que, en general, la mayor intensidad en la observancia religiosa conlleva también una mayor adhesión a las normatividades sexuales de las instituciones religiosas, católicas y evangélicas. No obstante, hemos señalado también que una diferencia mayor, tal vez la más notable de este estudio, se ubica al interior de la propia observancia religiosa. En efecto, destacan dos elementos fundamentales. Por un lado, la menor influencia de las instituciones normativas religiosas sobre los observantes hombres, de modo tal que estos muestran menos diferencias respecto de los no o los menos observantes, advirtiéndose también una mayor influencia sobre las mujeres, en cuyo caso la diferencia entre observantes y no observantes es mayor ${ }^{25}$. Por otro lado, al interior de la población observante, particularmente las mujeres, se presenta una diferencia entre la observancia católica y la evangélica, produciéndose efectos diferenciales: la brecha entre observantes y no observantes católicas es menor que la brecha existente entre observantes y no observantes evangélicas, siendo notable entre estas últimas.

Así, las mujeres observantes católicas presentan una respuesta de individualización, es decir, las personas asumen para sí las decisiones y opciones respecto de la sexualidad, independientemente de si tales decisiones y opciones corresponden o no con las prescripciones normativas religiosas. A su vez, las mujeres evangélicas observantes presentan una respuesta de subjetivación comunitaria, es decir, las personas reconocen pertenencia e identificación con un grupo o comunidad religiosa y se orientan por las normatividades sexuales de dicha comunidad. La primera respuesta, individualización, más estrechamente asociada a la población católica, particularmente en relación a las mujeres observantes, implica que la observancia religiosa no necesariamente implica construcción de vínculos entre los y las observantes (no genera comunidad) y, con ello, condiciones grupales para el reforzamiento de la norma. Las mujeres católicas pueden adoptar métodos anticonceptivos en contraposición a las prescripciones y proscripciones de la institucionalidad religiosa católica, sin por ello reducir o afectar sus niveles de observancia, es decir, de frecuencia en la concurrencia a los servicios religiosos. La

25 En general, en todos los ámbitos se observa una mayor influencia normativa de las instituciones religiosas sobre las mujeres que sobre los hombres, ya sea católicos o evangélicos (iniciación más temprana, contextos más múltiples de iniciación, mayor número de parejas, repertorios sexuales más variados, etc.). 
segunda respuesta, subjetivación comunitaria, aparece más estrechamente asociada a la población evangélica, particularmente en relación a las mujeres evangélicas. Estas tienden orientarse por una moral comunitaria, por normas cuya adopción se presenta como un signo de pertenencia y continuidad de la relación con la comunidad (testimonio). Es esta subjetivación comunitaria la que afirma la cercanía y sujeción a la norma; ésta no constituye sólo una cuestión individual o personal sino, sobre todo, una condición de permanencia y continuidad de la comunidad. Sobre todo, el sentido de la sujeción a la norma trasciende al grupo de pertenencia local y se ubica en referencia al conjunto de la sociedad: la consistencia testimonial, incluyendo la sexualidad, se dirige entonces a las mayorías, a aquellos que no profesan la religión o no se sujetan por las normas religiosas respecto de la sexualidad. Para un individuo evangélico, lo que se juega en sus comportamientos sexuales no es sólo una cuestión de consistencia interna sino, sobre todo, una forma de afirmación de la vigencia y la eficacia de la norma en el contexto de una sociedad en transformación; ahí radica su capacidad testimonial, allí se reside su poder simbólico.

Hemos planteado también la existencia de un efecto de la organización social y cultural de las relaciones de género, tanto de la adscripción como de la observancia entre mujeres y hombres. Como hemos señalado antes, en la situación de practicantes en las iglesias existen muchas más mujeres que hombres. Al mismo tiempo, como hemos mostrado precedentemente, estos últimos se encuentran en las generaciones sometidos a menor efecto de la pertenencia y observancia religiosas. Puede sugerirse que antes y ahora, la última no opera como compulsión ni coacción. Aquí reside una diferencia fundamental en las relaciones entre las instituciones religiosas y las mujeres y los hombres. Puede sugerirse, complementariamente, que para las mujeres existe una coacción antigua a la observancia, y su función estaría justamente en producir adhesión al discurso normativo institucional, a la vez que ser sometidas al control institucional y comunitario sobre sus prácticas.

Finalmente, hemos mostrado también los efectos de la secularización en una reducción de la adhesión en el ámbito de las prácticas, en el orden del hacer, respecto de los discursos normativos sexuales de las instituciones religiosas, católicas y evangélicas. Se trata de unos efectos producidos en el curso de las generaciones. Desde las generaciones mayores a las más jóvenes. Como hemos señalado antes, los efectos históricos han tenido en las mujeres su objeto, por tanto, las transformaciones han sido más intensas entre ellas, son éstas más propiamente han reducido su adhesión en materia de prácticas. $\mathrm{Al}$ mismo tiempo, puede sugerirse la existencia de una reconfiguración de tales relaciones, de una nueva conexión entre normatividad religiosa y normatividad generacional en contexto de procesos de 
secularización. En este sentido, por ejemplo, más allá de la observancia, incluso de la pertenencia, aún cuando las generaciones de mujeres jóvenes abandonan la iniciación marital, la inmensa mayoría lo hace en el contexto del pololeo -creyentes y no creyentes, practicantes y no practicantes-, es decir, el contexto relacional se torna una orientación normativa secular que aparece recuperando igualmente un sentido religioso, el amor; mientras las generaciones de hombres jóvenes, continúan disponiendo, igual que lo hicieran las generaciones más antiguas, de amplios contextos, más propiamente no relacionales ni amorosos.

\section{Bibliografía}

Adimark. (2005). Encuesta de Opinión Pública Los católicos opinan. Septiembre 2005. Santiago.

Blancarte, Roberto. 1993. Modernidad, Secularización y Religión. La Iglesia Católica, el Estado y la Sociedad Mexicana en el Umbral del Siglo XXI, en: Blanco, Joaquín y Woldenberg, José (Comps.) México a Fines de Siglo, Tomo II. México.

Bourdieu, P. (1988) La ilusión biográfica, en bourdieu, P. Razones Prácticas. España: Granica.

Bozon, Michel. (2002). Sociologie de la Sexualité. Nathan Editions. Paris. No 128.

- (2004). La nouvelle normativité des conduites sexuelles ou la difficulté de mettre en cohérence les expériences intimes, en [J. Marquet (dir.), 2004, Normes et conduites sexuelles. Approches sociologiques et ouvertures pluridisciplinaires, Academia-Bruylant, Louvain-La Neuve, pp.15-33]

- (2005). Femmes et sexualité, une individualisation sous contrainte, en M. Maruani, (dir.), Femmes, genre et société. L'état des savoirs, Paris: La Découverte, p.105-113.

El Mercurio-Opina. 2006. Encuesta de Opinión Pública, Marzo 2006. Santiago, Chile

FLACSO-Chile. (2001). Encuesta Nacional. FLACSO-Chile. Santiago.

Fontaine, A. (1991). Retrato del movimiento evangélico a la luz de las encuestas de opinión pública. Revista Estudios Públicos No. 44 Santiago, Chile.

Godard, F. y Cabannes, R. (1996) Uso de las Historias de Vida en las Ciencias Sociales, Centro de Investigaciones sobre Dinámica Social Serie II". Bogotá: Universidad del Externado de Colombia, julio.

Godoy, O. (2002). Creencias y prácticas religiosas en chile: un caso de inconsistencia. Revista Estudios Públicos n 85 (verano 2002). Centro de Estudios Públicos. Santiago, Chile.

Heilborn, M. L., Dias Duarte, L. F., Peixoto, C. y Lins de Barros, M. (2005). Sexualidade, familia e ethos religioso. Brasil: Editora Garamind Ltda.

Hill, M. (1976). Sociología de la religión. Madrid: Editorial Cristiandad. Lalive, C. (1968). El Refugio de las Masas. Santiago: Editorial Pacífico. 
Maduro, O. (1978). Religión y Conflicto Social. México: Centro de Estudios Ecuménicos.

Moscovici, S. (1981). Psicología de las minorías activas., Madrid: Editorial Morata.

Palma, S. (1996). Chilean Pentecostalism from de Perspectiva of its Specific Organisational and Experiential Features: A Study of the Group Process among the Poor. Ph D Thesis. University of London. London.

Pontificia Universidad Católica-ADIMARK. (2008). Encuesta Nacional Bicentenario. Pontificia Universidad Católica. Santiago, Chile

Programa de Naciones Unidas para el Desarrollo. (2002). Desarrollo Humano en Chile. Nosotros los chilenos, un desafío cultural. Santiago: PNUD.

Valenzuela, E. (2002). Religión y moral en contexto comparado. Revista Estudios Públicos, $n^{\circ} 85$. Centro de Estudios Públicos. Santiago, Chile.

Fecha de recepción del artículo: 5 de diciembre de 2008.

Fecha de aceptación del artículo: 30 de diciembre de 2008. 
